\title{
RESQ for FLASHMEM, Inc.: An IS Teaching Case
}

\author{
Laurie Schatzberg \\ University of New Mexico \\ Albuquerque, NM 87131 USA \\ rattner@unm.edu
}

\begin{abstract}
Their manager has promised that the aging factory would be the first to implement RESQ, a resource estimator and scheduler developed in-house at FLASHMEM, Inc. While RESQ clearly fills an urgent need for better CPU utilization and management decision-making, Jamie Barton and Angelo Rodriguez now recognize the impossibility of the current plan for their factory.

The case provides a brief history of RESQ and background of the players and culminates in the meeting between the IS and the manufacturing members of an IS development team. It focuses readers on some pervasive analyst-user issues including their respective roles in the development process, project management, the role of IS in a mature/commodity industry, vulnerabilities arising from in-house developed systems, and the implications of enforcing company-wide application standards.
\end{abstract}

Keywords: system development, end-user interactions, conflict, manufacturing information systems

\section{Tuesday Morning}

Angelo Rodriguez and Jamie Barton are visibly shaken, and it isn't even 7am. They and their sprawling papers cover nearly half of the round meeting table. Rodriguez is the day shift Manufacturing Lead, and Barton is the night shift Lead at FLASHMEM's South West factory. This morning, they are brainstorming about the possible consequences of this latest problem on the manufacturing floor. They knew they'd be facing a veritable firing squad at today's 8am operations meeting.

Equipment is known to fail, but Rodriguez or Barton should have responded to the warning signs days ago. The EB70 had been operating on borrowed time for too long, since its quarterly preventive maintenance was due more than two weeks ago. As they transitioned from Barton's night shift this morning, he and Rodriguez authorized the shut down of the EB70 for a major maintenance overhaul that will cripple production for at least four days. Further, the out-of-spec

Material published as part of this journal, either on-line or in print, is copyrighted by the publisher of Informing Science. Permission to make digital or paper copy of part or all of these works for personal or classroom use is granted without fee provided that the copies are not made or distributed for profit or commercial advantage AND that copies 1) bear this notice in full and 2) give the full citation on the first page. It is permissible to abstract these works so long as credit is given. To copy in all other cases or to republish or to post on a server or to redistribute to lists requires specific permission and payment of a fee. Contact Editor@gise.org to request redistribution permission. production runs leading up to this failure will cost FLASHMEM millions. In this commodity industry, production losses quickly lead to lost customers. Clearly Barton and Rodriguez shared responsibility for this preventable loss, and they were preoccupied with this immediate disaster as they waited for the IS folks to show up for their 7:15 meeting.

Ten days ago, Rodriguez had scheduled this meeting using the company-wide calendar tool. The stated purpose of the meeting is to iron out some problems deploying RESQ in the factory. He had wanted to meet sooner than today, but this was the earliest that all four of them would be available for more than 30 minutes. If Eli Bethel from IS hadn't agreed to come in an hour early, even this meeting wouldn't have been possible.

Their boss (who is also the factory Manager), Mitchell Haddon, had assigned to Rodriguez the rollout of the new production tracking system aptly called RESQ (an acronym meaning Resource for Estimates and Scheduled Quantities), and they needed to focus on that priority for the next 45 minutes. Given their current crisis, however, he and Barton both wished they had the next hour to plan for the 8am meeting.

\section{Resource for Estimates \& Scheduled Quantities (RESQ)}

RESQ is a hot new technology at FLASHMEM. It organizes estimated and actual production data for the hundreds 


\section{Teaching Case: RESQ for FLASHMEM}

of production steps and for the dozens of products while giving users a PC spreadsheet front end. With the click of a mouse, RESQ produces on-screen reports and charts of production by week, shift or day going back for months. With another click, RESQ displays the production goals, along with progress toward those goals. The data is refreshed from the database every 15 minutes, thereby providing nearly real-time access to production information. RESQ can help at all levels in production management. Production workers can measure their own progress toward daily goals, can see when work in process (WIP) "bubbles" are expected at their machine, and when they'll have time windows for breaks and scheduled mini-maintenance. Production supervisors can schedule work through their areas by viewing the upstream and downstream WIP at known bottlenecks along with the production goals for their shifts. Upper management can use RESQ to identify and track trends. It is one tool in a strategy to increase overall productivity, a strategy that includes moving decision-making closer to production floor and establishing consistency in decision-making methods.

RESQ embeds business and production rules into its algorithms. The rules originate with management policies and business rules and govern prioritization of WIP, utilization of equipment, and scheduling of maintenance. Many of the present problems at the South West factory stem from having considered each of these decisions independently from one other, and RESQ enables an integrated approach.

Understanding the interactions and ultimately finding the right balance among conflicting constraints is a daunting task. RESQ performs that task. RESQ provides exactly the type of information that supervisors need to keep WIP moving through the factory and to manage equipment utilization issues. RESQ is a resource to enable FLASHMEM to plan production, and then to work "to" the plan instead of "despite of" it.

\section{Brief History of RESQ}

Two veteran employees (Dawn Schipper, Director of Information Systems Services and Wesley Rice, Vice President of Manufacturing) had developed RESQ at FLASHMEM's facility in Vancouver: Schipper was the driver behind the RESQ initiative. She envisioned RESQ as a means to remove administrative computing loads from the computers that also run the production line. In the highest performing factories, production was slowed by an estimated $7 \%$ because of simultaneous CPU demands by both production and management reporting. These factories had installed additional servers, and partitioned the data, but found that the increased network traffic mostly offset the hoped-for improvements in response time.
The whole idea of RESQ was to move production reporting to a client-server environment, thus freeing up constrained mainframe computing power for production. Importantly, the client-server approach supports the company-wide movement toward more decentralized decisionmaking. Such change would require not only major infrastructure investments, but also an enormous commitment to evolve the corporate-wide standards to this new architecture.

Schipper understood that while production staff was comfortable with current methods, production supervisors and managers were increasingly aware of the personal price they paid for inadequate access to information. She anticipated that they would embrace reasonable levels of change if RESQ would ease those problems. Thus, she had to sell manufacturing supervisors and managers on their own terms. For example, they could relate to the power of RESQ in increasing throughput and productivity. That these improvements accrue, in part, from better CPU utilization is of no interest to the manufacturing organization.

To garner the necessary manufacturing support, Schipper first sold the idea to Rice, who quickly understood the potential for enormous benefits to manufacturing. As the top Manufacturing manager, Rice used his expertise, contacts, and influence to design the core reports and user interface. Together, Schipper and Rice designed the scope and the architecture of what was to become the core of consistent manufacturing planning methods and standardized reporting - from the shop floor to the corporate offices. From the IS perspective, standard resources meant huge cost savings in support, training, employee development and relocation, and new-factory introduction. From the manufacturing perspective, the initiative meant increased productivity and throughput. Both issues go directly to FLASHMEM's bottom-line.

Schipper and Rice soon spread their enthusiasm to regional management as they demonstrated prototypes and incorporated feedback from the regions and individual factories. Over a period of four months, RESQ had matured from a sketch to a semi-active prototype. The core functionality was defined and refined, and rumors spread throughout FLASHMEM that a major operational breakthrough was imminent. The informal publicity was exactly what Schipper and Rice wanted, since it would build interest and attention on their presentation at the upcoming Manufacturing Technologies Conference.

When Schipper and Rice demonstrated RESQ at the annual FLASHMEM Manufacturing Technologies Conference, they became instant corporate heroes. In creating RESQ, they had cracked a tough problem, and their success showcased the best of cross-functional teamwork. 
Conference halls, personal digital assistants and e-mail rooms were buzzing with news of this user-friendly production management tool.

\section{Current Status of RESQ}

Mitchell Haddon, manager of the aging South West factory was among the most enthusiastic supporters of RESQ - a tool he saw for the first time at the Conference. At the Executive Closing Session, Haddon went so far as to commit to convert his South West factory to RESQ before fiscal year end.

Haddon saw that success with RESQ could save the South West factory. Since the South West factory is far from high performing, saving it would become a high profile FLASHMEM accomplishment. High performance seemed impossible without radical changes or drastic measures. Haddon knew that time was running out until Corporate decided on the South West factory's fate.

Three weeks after the Conference, in a move that surprised everyone, Schipper left FLASHMEM to start her own software development company. Her untimely departure paralyzed RESQ development, since she took with her most of the detailed system knowledge. Factory personnel involved with RESQ scurried to create basic documentation from their scattered notes, and to form a cross-factory team to reverse-engineer RESQ so it could still be viable for FLASHMEM's future.

\section{Current Production Reporting Meth- ods}

Most workers in the factories had only limited computer and decision-making experience. Typically, to run their equipment they used VAX terminals that were specially outfitted to withstand a factory environment. They depended on supervisors to review hardcopy output of the reports needed for daily production decisions - and to tell them what to run. They learned to use some predefined VAX-based reports that they often kept running during an entire shift - since navigating to the report generator was so cumbersome. Most supervisors had learned from their predecessors which VAX reports to use and how to access them. They all knew there were hundreds of VAX reports available, but almost no one knew how to discover what they contained. Consequently, they would often commission a new report to meet an apparently-new need. Manufacturing management was in the same predicament as supervisors were with respect to the VAX reports, but they did have some experience using Windows-based applications. In fact, they often developed their own PC-based reports pulling data from the VAX. As difficult as it is to manage the VAX reports, these spreadsheet models were even more so. It was widely believed that not one person in all of FLASHMEM knew the whereabouts of all these reports, let alone their contents, logic or current usability.

The general methods of reporting are the same at all FLASHMEM facilities, but there are no standards for report design, timing, naming, archiving or distribution. Production data is continuously downloaded from the manufacturing process equipment and stored. The equipment itself is run with individual process controllers drawing data from the VAXes as well. The real drain on the VAX stems from the reporting methods, however. Any user has the authority to create and run his or her own reports, and there are literally hundreds of reports serving users in manufacturing, scheduling, and management. The proliferation of user-defined reports is a problem in its own right, but in addition, these $\mathrm{I} / \mathrm{O}$ demands interfere with production.

Compounding the I/O demands on the VAX's are the problems stemming from poor information management. There is no data dictionary, and many data structures take on user-specific meanings - making it impossible to reconcile the data reported across the organization. At best, the report designer knows exactly what the report is supposed to mean for the first few weeks of the report's life. After that, in the absence of painstaking documentation, human memory fails. Further, since there is neither a dictionary/directory of existing reports nor standard naming conventions for new reports, there is tremendous redundancy over time in report creation and maintenance. There is no way to determine when a given report becomes obsolete.

\section{Remaining Participants in the RESQ Meeting}

Eli Bethel Bethel is a seasoned and very talented IS developer, and one of the IS group's best programmers. He's been with FLASHMEM for nearly a decade, and worked for a textile producer in the Middle East for 12 years prior to that. Known as a feisty, no-nonsense guy, he has little patience with the vagaries that most customers present to him and his IS teams. Involved in several other ongoing projects, Bethel has been reverse engineering RESQ in order to make it work in the South West factory's heterogeneous computing environment. His work in this regard has become quite visible across FLASHMEM.

He has enjoyed programming for the new client-server environment, since he knows these skills will keep him competitive in the marketplace. His "read" on RESQ, however, is that it is another of Haddon's "Management Initiatives of the Month" - and that Haddon will soon pull the resources and/or lose interest. Nonetheless, Bethel had become the RESQ "guru." Bethel displays the cynicism 


\section{Teaching Case: RESQ for FLASHMEM}

sometimes associated with scientists frustrated by management.

Lee Radnor Radnor is an independent MIS consultant who has guided several other projects for FLASHMEM in the past. Most recently, Haddon's predecessor contracted with him for a special WIP prioritizing project she wanted in the factory. Ironically, the predecessor moved up and out the week before Radnor started, leaving Radnor with an irrelevant contract. Not wanting to return the corporate resources for the systems consultant, Haddon convinced Radnor to support the RESQ project, instead.

Radnor quickly found that the action lay with Bethel in the IS department. Radnor is personable, and listens intently to his customers. With about 25 years of experience in applying IS to manufacturing environments both in the US and abroad, he also understands the enormous conceptual and language gaps between typical manufacturing and IS organizations. Their worlds seem completely different, and it is almost painful for them to participate in meetings together. He attributes many of his successes and all IS failures to his ability (or lack thereof) to improve the quality of communications between IS and its customers.

Radnor focused on the manufacturing (user) side of reverseengineering RESQ while Bethel focused on the technical underpinnings. Radnor worked each of the functions, studied their logic, and reconciled query results back to the original data. He documented his findings and raised alert-flags when the data did not reconcile, when the logic was unclear or clearly wrong, and when the presentation was ambiguous or the interface cumbersome. He had shadowed a few manufacturing folks to get a better feel for their work and issues, and used that knowledge to trouble-shoot RESQ. He demonstrated RESQ to a few manufacturing workers in the pilottest group, and incorporated their input to improve RESQ. Those workers would have been ideal to pilot-test RESQ more formally, but for the most part, they were not interested.

Despite the lack of support from the South West Manufacturing group, Radnor understood his mandate to transfer his deepening RESQ knowledge to FLASHMEM. Radnor began to train trainers in other factories and to coordinate FLASHMEM's official training and documentation initiatives. Further, he spoke at length a number of times with Haddon, to apprise him of the resistance he was experiencing from the ranks. He suggested that Haddon make himself a more visible champion of the project.

\section{The RESQ Meeting}

It's about a month since the Conference. At 7:15 Eli Bethel and Lee Radnor cross paths in the hallway on their way to the meeting with Barton and Rodriguez. Rodriguez and Barton push their "crisis" papers to one side and fall silent as Bethel and Radnor enter the meeting room together. Bethel instinctively sits directly across from Rodriguez and Barton, while Radnor deliberately positions himself in between the manufacturing duo and Bethel. He recognizes the familiar tensions between Manufacturing and IS groups. He nods in greeting to Barton and Rodriguez as he sits down.

Spending no time on pleasantries, Bethel barks toward Rodriguez, "This is your meeting. You scheduled it as 'RESQ Implementation Issues' on my electronic calendar, but you never sent the agenda. What're we doing here?"

Rodriguez, ignoring the tone, says, "We've worked with RESQ some and have tried to get the Supes (supervisors) in the pilot group to use it, too. Their response has been miserable, and I've figured out how we can ease them into it."

"Instead of getting them to use the core RESQ, I want to give them a simple WIP prioritizing utility using a spreadsheet. It's something they've been wanting for a long time, so I'm sure they'll use it. Then, while they're on the PC, we tell 'em to check out the rest of RESQ. Y'know slip 'em the medicine covered with sugar. Jamie and I have talked about it and it's so clear that this is the way to go. The training is minimized, and we get their attention. Y'know once they start talkin' up this utility, they'll quickly fall in line with RESQ."

Barton took over the pitch, scrawling circles and arrows on the white board to describe the new utility, and giving paper copies of the sketches to Bethel and Radnor. "Here's the way the workers currently prioritize WIP. Problem is the data they're using is too old, and sometimes is incomplete. We just never know for sure. We want to give them the data at the right time - and also recommend the priorities. They'll quickly see that their lives are easier by using the spreadsheet utility. Without realizing it, they'll have learned to use the PC's too!" Both he and Rodriguez exhaled, having delivered clear requirements for the new application. They waited for ensuing silence to be broken, certain that the IS folks would share their enthusiasm for this new approach. They were very wrong.

Bethel was incredulous and began, barely able to contain his disgust with the idea, "So you want to drop RESQ and create this new..."

Rodriguez interrupted, “No, Eli, not drop RESQ, just do this spreadsheet for us and then we can move 'em to RESQ!" Rodriguez saw that Bethel was not convinced, so he continued his pitch, "We just can't get them to use 


\section{Schatzberg}

RESQ now. They don't see how it helps them. You can just make this utility another "tabbed page" in the RESQ spreadsheet!"

"How can you know RESQ isn't viable?" Radnor interjects. "I've been demonstrating RESQ in 1-on-1 meetings with some manufacturing reps. I've analyzed RESQ usage stats, and I see that there's been no other use by manufacturing. You complain about the pilot group, but why should they when you - their managers - haven't touched it since the initial announcement last month, either! They just follow your lead. We need to validate RESQ and the only way to do that is for manufacturing to use it with us."

Bethel attacks Rodriguez, "You aren't even using RESQ reports for the operations meetings?!? You sure are a poor excuse for a manufacturing liaison!"

Bethel started again, seeming to make himself more furious as he spoke, "This utility you describe has absolutely nothing to do with RESQ! When supervisors get what they want from this utility, why would they ever decide it'd be a good idea to browse RESQ?!? That's a ridiculous idea! It's like expecting they'll go shopping through old VAX reports when they get what they want from their own new report! They never do that and that's part of the reason for RESQ. This back-door idea is rubbish, and you know it!"

Radnor senses that the manufacturing guys are onto something, but he can't seem to get everyone on the same side of the fence to find out, and spoke in a calm voice as he continued, "You guys know that 'just adding a tab' onto core RESQ doesn't cut it. It violates FLASHMEM's standard applications principles. Even we consultants have to adhere to those standards. Core RESQ was ratified last week, and if you wanna change it, sell it to the steering committee. Until you do that, the most you can hope for is yet another standalone application."

Barton pushed back, "Listen, RESQ might be a great overall scheduler, but it doesn't give the detail we need on the floor. All we're saying is if you give us what we want, we'll try to use the other stuff." While he was at it, Barton added, "You MIS wizards are supposed to support us here, not peddle stuff we can't use! Manufacturing drives FLASHMEM!"

The fireworks continue, with Bethel again raising his voice, "Hey, don't get me wrong! I'll write you any $\$ * \#$ ! piece of code you want. You're just crazy for thinking that all of FLASHMEM manufacturing except the South West factory needs RESQ! Do you really think our factory is that different? And even if it is different, how can you possibly believe it should be? You're supposed to be turning this factory around, not protecting your problems here!"
Rodriguez again tries to improve the tone of the meeting by focusing on their common purpose, "Eli, you know as well as I do that Haddon is banking on RESQ to save this factory. He has no clue how things happen on the floor and is just waiving the RESQ flag to get some corporate attention. RESQ isn't only impractical here, it's impossible! We don't even have PCs in the factory, so how can the teams use RESQ? We can't afford their taking 15 minute 'strolls' back and forth to a PC that's not only out of their work area, but it's out of the factory in their team office! Moving production workers away from their equipment and terminals to remote PCs will cripple our production, not improve it!

"Even the supervisors have to come out of the factory to use shared PCs. It's just not practical to use RESQ the way Haddon wants, and the way the other factories are talkin'. Face it, we're an old factory. We just don't have the PCs in the factory to make this practical. We don't even have the floor space available to install them if we had more PCs. We figure if the supervisors get one thing they need from a PC, then we might work up to finding a use for RESQ. No way can we roll out RESQ the way Haddon imagines. No way!"

Bethel interjected, "Look, it's a little late to be complaining that you don't have the resources to do your job! You're within microns of the best resource scheduler known to the industry and you're lookin' the wrong way! Where was all this wisdom when you accepted the project? You're talking to the wrong people if you want 'out' of RESQ. Go talk to Haddon, and tell him that South West can't implement RESQ! After he shuts down RESQ here, then you get back to me about this WIP priority thing. Until then, the future of RESQ here is in your hands."

Their meeting room had been scheduled for an $8 \mathrm{am}$, and those people were gathering outside the door. Barton and Rodriguez collected their papers. Radnor had a clear sense of déjà vu as they all left the room.

\section{Epilogue}

The South West factory never did implement RESQ. By year-end, the South West factory was officially slated for conversion to a training facility and most of the employees were transferred within the company. Bethel left under tense circumstances. Building largely on Bethel's work, RESQ was successfully reverse-engineered and fully deployed in all the other FLASHMEM factories. The training materials were copyrighted and proliferated throughout FLASHMEM. FLASHMEM estimates that once RESQ reaches steady state in a given factory, throughput increases by about $15 \%$. 


\section{Teaching Notes \\ By Case Section}

\section{Tuesday Morning}

Teaching note 1: From a technology perspective, discuss calendaring software and its use in the field. This technology is one that requires critical mass to be successful; that is, the use must be widespread (and championed from the top) in order to be practical organization-wide. From a strategic perspective, discuss the implications for IS in a "commodity" industry where high efficiency and low cost are essential. IS must focus on productivity-enhancing applications with clear, short-term payback. This environment is no place for experimental or even state-of-the-art new applications. IS must build on its existing knowledge and resource bases. Finally, remind students that while this case focuses on issues within a single facility, the ideas apply to global and international firms and work teams - where they are much more complex to handle.

\section{Resource for Estimates \& Scheduled Quanti- ties (RESQ)}

Teaching Note 2: Consider the "refresh" rate from the database. Students may not understand that the "right" datarefresh rate is a function of the data volatility for the particular application. In a manufacturing environment, the process control data is much more volatile (and thus requires instantaneous currency) than management-oriented summaries. Thus, whether 15 minutes is too old or too ambitious must be answered from the perspective of the users' needs.

In this case, RESQ is aimed at generating summary reports (for example, production goals for this hour/shift/day/week and the output toward those goals), and 15-minute currency gives users real-time "enough" for their purposes. Note that the reporting in question here is not "process control" which, even in the South West factory, is subject to both real-time monitoring and control. Instead, this case focuses on the needs of supervisors and managers who are making longerterm decisions and commitments to internal and external customers.

It is important for MIS students to consider the differing needs among user groups, and the impact this has on creating new applications, and the varying types of customers. For any given assignment, MIS staff should define the applications users and managers as customers, and interact with them as such. Even with a solid customer-orientation, stu- dents often have difficulty defining and adhering to the scope of a particular application. For good discussion on these related issues, challenge students to define the intended users of RESQ. The intended users, in turn, comprise part of the "customer base" for the application. The users' managers, the funding sources, and standards groups (in this case, the RESQ steering committee) comprise other customers.

It may also be useful to discuss the conflicting constraints, so students develop a deeper understanding of the environment for which FLASHMEM is designed. WIP prioritization schemes are learned in Operations Management courses, but they can be summarized here. One common scheme is FIFO, with variations based on customer information, lateness, processing "bubbles," or in-house testing needs. Thus, WIP prioritizing is, in itself, an issue that crosses functional boundaries. Equipment utilization directly impacts capital costs - firms must decide whether to invest in fewer machines running at relatively higher utilization or more machines running at lower utilization. This decision cannot be made in isolation, since utilization rates impact maintenance (scheduled and non-) and flexibility. Finally, while scheduled preventive maintenance is key to ensuring steady production, each occurrence interrupts production flow. How can management schedule maintenance to minimize disruption and ensure excellence? Decisions on all three of these issues impact the others. Students' mental models of manufacturing usually are quite limited. Encourage them to examine these issues in the context of a real firm that has hundreds of machines, each of which can perform multiple production steps.

The source of knowledge for RESQ rules and algorithms is FLASHMEM manufacturing personnel, and this concept will be revisited later in the case as well. While RESQ can be termed an expert system, reinforce with students that ultimately, the sources of the knowledge embedded in RESQ (and necessary to maintain its currency) come from human experts.

Management establishes guiding principles, and employees closer to the floor (supervisors and workers) refine and implement them. For example, FIFO lot priority rules are established for the factory as a whole. However, good workers often recognize time- and processing-savings opportunities by "tweaking" the rule (advance a particular lot to reduce setups). With RESQ, such local, informed decision-making can be routinized and standardized by embedding the workers' deep knowledge of how to handle "what if"s. Thus, the ad hoc and potentially risky exceptions can be made explicit, analyzed, and, if appropriate, converted into formal business rules. 


\section{Brief History of RESQ}

Teaching Note 3: Focus students on the basic ingredients of successful information system development: the active participation of management, IS, and end-users. Note that Schipper and Rice engaged Manufacturing and IS to develop support "from the ranks" and then incorporated their requirements into the emerging design. They, themselves, also represented management. Schipper also understood their need to sell the idea to manufacturing based on the manufacturing benefits - and not the benefits to IS.

From a technical perspective, discuss the shift away from sharing mainframe resources by both manufacturing and management. In this regard, discuss the conflicting demands for uninterruptible computing power to run the hundreds of machines and the need for real-time production information to drive the schedules and plans. Students often think of all companies running on a 9-5 schedule, and may suggest running administrative reports during the night. Manufacturing facilities, especially those competing in commodity markets, are running $24 \times 7$. Further, since management (and engineering) support is usually "thin" during the off-shifts, production is often greater! Focus students on the IS issues arising in $24 \times 7$ environments.

Finally, for a monetary feel, have students "run some numbers" as to the impact that a 7\% production increase might bring the firm. RESQ is focused on an ancillary product line for FLASHMEM. The product is a commodity product with slim margins, but it is a good complement to the firm's cash cow products. Making plenty of assumptions, assume that current production is 200,000 widgets per month at the South West factory. An increase of $7 \%$ would mean that 14,000 additional widgets could be produced and sold. If the selling price of each widget were only $\$ 10$, FLASHMEM would realize $\$ 140,000$ of additional revenue per month. Thus, management can properly interpret that the current bottlenecks cost this one factory $\$ 140,000$ per month - and there are several factories world wide with this problem.

\section{Current Status of RESQ}

Teaching note 4: Schipper's leaving was unlucky for FLASHMEM, but it underscores the vulnerability associated with developing applications with a skeletal crew, and also provides an opportunity to discuss both intellectual property and professionalism issues. The case suggests that FLASHMEM lacked "depth" on the IS side of RESQ. Good project management would not have allowed such risk to be taken, and instead, the project team would have included additional IS talent as well as better documentation. None- theless, special projects are often thinly staffed - management (unconsciously?) discounts the attendant risks.

Schipper, as do most employees, had the right to move her career outside of FLASHMEM whenever she chose. As a condition of her employment, however, she had signed a contract that precluded her from taking outside of FLASHMEM any work she'd developed or contributed to (intellectual property) while employed there. Her development work was all FLASHMEM information resources and actively protected by their information security programs. Further, Schipper was also precluded from competing directly with FLASHMEM for a period of three (3) years after leaving FLASHMEM.

Schipper left "on good terms" and of her own choosing, after making noticeable positive contributions to her employer. Those who remained at FLASHMEM to carry on the RESQ work, however, probably judged that she acted improperly by leaving so suddenly without providing good transfer of RESQ knowledge and without participating in a transition of RESQ leadership.

\section{Current Production Reporting Methods}

Teaching note 5: This section introduces a few key MIS issues - that center on the tensions between developers and users of information products. The central tension is that information users should be viewed and treated as customers of the information products (reports \& forms) that IS develops.

Customers' demands for information should lead directly to system specifications to deliver those products. In practice, however, IS professionals have rarely internalized this perspective. Compounding the problem is that our customers may not recognize their own challenging role in the process of developing strong information products. Customers' needs change often, and when there is a time lag before IS can meet their needs; of course, those needs will likely have changed. The natural result of IS inability to instantaneously meet the dynamic information needs of our customers is that they begin to create their own information products using whatever tools are available to them. For non-recurring information needs, this is an excellent solution; for needs recurring in the organization, the practice leads to longer run problems as outlined below.

The first issue is a common downside of user-designed reports: lack of discipline in their creation and maintenance. Because end-users create what they need, when 


\section{Teaching Case: RESQ for FLASHMEM}

they need it, with no supervision or approval by MIS professionals, the result is a messy proliferation of potentially meaningless reports. Focus on the value of dictionaries defining data structures, on a process of review and oversight for the creation of new shared reports, and of a lifecycle approach to those reports (identify the purpose, audience, and conditions under which the report is needed/obsolete). Without unduly burdening the reporting process, IS and management need to take ownership of reporting resources. Firms with a wide proliferation of PCs commonly experience this same issue. The cost to the organization of such unmanaged redundancy can be enormous.

The second, subtler issue at this point in the case is that the intended users of RESQ are unfamiliar with a PC front end, since they work daily with a VAX/mainframe interface. This lack of exposure may be astonishing for students who would be hard pressed to identify anyone who doesn't work with PCs. Yet, in a production environment, PCs are not the norm. Certainly management is comfortable using PC-based applications, but the production workers are not (yet) exposed to PCs as part of their work environment. Those who have PC skills developed them on their own time. Focus students on the need for IS professionals to have a working knowledge of the users' domains and for the development process to include a transition path for users. This knowledge is one way to distinguish outstanding MIS professionals.

\section{Remaining Participants in the RESQ Meeting}

Teaching Note 6: This section raises several professional issues. First, note that both Eli Bethel and Lee Radnor have international experience. Increasingly, IS professionals must be groomed to work in and with not only different firms and different industries, but also different societies. This concept is useful to touch on, but there is little in the case that focuses on culture per se. Bethel's cynical personality can stimulate philosophical discussions around MIS professionals' need to find a good organizational fit. Not everyone can work in a large firm; not everyone can work as an entrepreneur. Radnor, an entrepreneur, has a keen focus on users. It is likely a reason for his success. He recognizes the language and culture difference between IS and manufacturing and the impact that gap can have on project success and personal satisfaction.

A potential trouble spot is that when his hiring manager left, Radnor was subsequently redeployed. From the sparse details, it appears that he was moved to a viable project, but the students should analyze the potential pitfalls of such a "bait and switch" from customers. Professionalism and per- sonal ethics dictate that consultants and workers accept assignments for which they are qualified or capable of completing with the available resources. Brainstorm with the students on issues that Radnor should have considered and discussed with Haddon before accepting the new assignment. (Given the events that will unfold in this case, assess the extent to which Radnor should have advised Haddon to stop the project.) Explore the contrary perspective that no additional effort on his part was warranted

\section{The RESQ Meeting}

Teaching Note 7: An extremely hostile meeting among members of a "team." Students will recognize that the focal character, Eli Bethel, set the tone of the meeting. What they may not realize is the extent to which the other three chose to allow that to happen. Emphasize that excellent interpersonal communication, including conflict management, would enable any team member to assert control and neutralize the hostility in this type of setting. Focus students on the need for meetings to have an agenda, for a person to be assigned the role of gatekeeper, and for that gatekeeper to keep the meeting focused on the agenda. Disagreements and conflicts are essential for teams to experience - managing them enables the work to progress and the participants to grow. Personal attacks have no place in a work environment, and it takes maturity, training, discipline and creativity to discover the many different ways of working with many different styles. Students who have worked in dysfunctional teams may recognize the frustration described. They may not, however, yet possess the tools to avoid re-creating such dysfunction. Roleplaying, while uncomfortable for some, may be a superb technique to demonstrate good practices.

As Bethel points out, deeper issues are clear. If manufacturing team members believed that the project was infeasible from the start, they should have said so. Good project management mandates a series of go/no-go decision points, and they all failed to exercise that discipline. Even if overzealous Haddon had overridden their objections, the discussion would have lead to more realistic project goals and expectations.

The manufacturing reps' failure to implement the pilot testing is an example of "passive resistance" by unwilling participants. They choose to do nothing explicit to sabotage the project, but simply miss agreed-upon deadlines and fail to complete deliverables. Again, good project management should respond to this type of behavior with clear, swift consequences. 


\section{Schatzberg}

Finally, notice that the manufacturing team members were concerned with some other problem, when the meeting started. This observation leads to the discussion of teams and projects where members are also participating in other teams and projects. Students often assume that the scheduling and priority conflicts they experience during "school projects" go away in "real jobs" because everyone works for the same organization. The truth is that scheduling and priority conflicts persist. Discuss the implications, in the work setting, of team members placing differing priorities on a given project - and the need for management to make organizational priorities clear.

\section{Additional Teaching Notes}

Teaching aim: This case works well as an introductory case in advanced courses or as an ending case in introductory courses. It raises several issues that enable the instructor to preview or review concepts that are covered in more detail through projects, cases, hands-on labs, and co-ops or internships.

Learning objectives: Students should grasp the complex nature of systems development in a dynamic environment. Many of the main points should be recognized by more experienced students, and should be discussed by the class. Students who have only learned about MIS from textbooks and class projects should at least be able to contrast the wellstructured class experiences with the complications in the case. They should recognize that sometimes there is no clear right answer, only right approaches to the problems presented.

This case presents a rich set of "typical" systems development issues, and is based on recent experience in a high technology manufacturing firm. It is recommended that students read the case without the brief Epilogue, so that they will focus on the rich set of issues it raises.

One potential source of conflict arises from IS members' lack of recognition that they only add value to the organization when they are participating in solving business problems. Using this provocative perspective, students should evaluate the interactions between Bethel/Radnor and Barton/ Rodriguez.

For systems developed without consideration of a threeschema architecture, changing platforms upon which applications run is a major undertaking, and as such requires strong and credible top-management support. Students may recognize that Haddon's reputation left him without credibility in his support for RESQ. (3-schema architecture refers to the physical model, the conceptual model, and the set of user models comprising information systems.)

As FLASHMEM is moving to a more decentralized decision-making philosophy, they are attempting to evolve their supporting IT in a similar vein. This transition is appropriate, and students should discuss the role of information systems in creating or enabling organizational change.

Organizations are vulnerable when they develop systems without skill "depth" and good documentation. Schipper and Rice received deserving accolades for the product they developed. However, they failed to create either the team or the documentation necessary to ensure RESQ's survival in FLASHMEM. Further, that team did not contain the necessary depth to withstand Schipper's leaving. The relative efficiency of a small team (Schipper and Rice) must be balanced with organizational history and learning afforded by larger, integrated teams.

Software design issues: corporate standards for tools ("core" RESQ). FLASHMEM uses such discipline to support the transfer of technology and people across factories. Standards save enormous sums on cross training, and create great portability for the staff to move around within the company. How can management balance the need for flexibility in individual factories with the need for economies of scale?

Introductory IS classes describe transaction processing, information management, and decision-support as serving separate types of IS users. Students should be able to identify these systems and their users in this case, and should recognize that the higher-level decision-making is inextricably tied to the business transactions (in this case, production).

Information resources management has apparently been neglected by FLASHMEM. Computer hardware utilization was allowed to creep to high enough levels to threaten production - the firm's lifeblood! The data has also been neglected as the unmanaged proliferation of VAX reports illustrates. The "extra" reports may seem harmless, since the storage of scripts that generate them is minimal. Students should recognize that the high cost is incurred from all the labor-hours devoted to repeatedly inventing and implementing the same thing. This management issue is also tied to the lack of a good repository.

Discuss openly the potential for strained relations between technical computer professionals and users. There remains a perceived intolerance on the part of these professionals with respect to users' ability to express their needs and 


\section{Teaching Case: RESQ for FLASHMEM}

communicate effectively. How does the training of IS professionals prepare them for the interface roles they'll have in IS organizations? Responsibility for excellence in communication lies with all participants, and this case provides an example counter-productive attitudes and interactions.

Additional points of professional interest include:

- The difficulty that the group had in scheduling a meeting time. Students without significant work experience often complain that scheduling team meetings is difficult because everyone has other obligations beyond school. They mistakenly believe that once they're in a full-time professional work setting, that problem goes away, "because then we'll all work at the same place." The calendar management and room reservation systems used at
FLASHMEM help with the tedium of finding a place and time, but do not get at the heart of the scheduling problem.

- Professional conduct. Discuss the responsibilities each of the four participants had to confront Haddon and to create clear go/no-go decision points in the project.

- Leaderless team. Discuss that the foursome had no apparent leader, and that one result is that the IS participants have moved in a different direction from the manufacturing participants. Apparently, communication within the team has not been effective, and no one within the team has established an effective liaison with Haddon, the project sponsor. 